\title{
Comparison of the effects of lactated Ringer solution with and without hydroxyethyl starch fluid resuscitation on gut edema during severe splanchnic ischemia
}

\author{
S.M. Lobo ${ }^{1}$, S.R.P. Orrico ${ }^{1}$, M.M. Queiroz ${ }^{1}$, L.M. Contrim ${ }^{1}$ and P.M. Cury ${ }^{2}$ \\ ${ }^{1}$ Serviço de Terapia Intensiva, ${ }^{2}$ Disciplina de Patologia, Departamento de Medicina Interna, Faculdade de \\ Medicina de Rio Preto, São José do Rio Preto, SP, Brasil \\ Correspondence to: S.M. Lobo, Laboratório de Sepse, Serviço de Terapia Intensiva, Faculdade de \\ Medicina de Rio Preto, Av. Brigadeiro Faria Lima, 5544, 15090-000 São José do Rio Preto, SP, Brasil \\ Fax: +55-21-17-3227-7589. E-mail: suzanalobo@yahoo.com
}

\begin{abstract}
The type of fluid used during resuscitation may have an important impact on tissue edema. We evaluated the impact of two different regimens of fluid resuscitation on hemodynamics and on lung and intestinal edema during splanchnic hypoperfusion in rabbits. The study included 16 female New Zealand rabbits ( 2.9 to $3.3 \mathrm{~kg}$ body weight, aged 8 to 12 months) with splanchnic ischemia induced by ligation of the superior mesenteric artery. The animals were randomized into two experimental groups: group I $\left(\mathrm{N}=9\right.$ ) received $12 \mathrm{~mL} \cdot \mathrm{kg}^{-1} \cdot \mathrm{h}^{-1}$ lactated Ringer solution and $20 \mathrm{~mL} / \mathrm{kg} 6 \%$ hydroxyethyl starch solution; group II ( $=7$ ) received $36 \mathrm{~mL} \cdot \mathrm{kg}^{-1} \cdot \mathrm{h}^{-1}$ lactated Ringer solution and $20 \mathrm{~mL} / \mathrm{kg} 0.9 \%$ saline. A segment from the ileum was isolated to be perfused. A tonometric catheter was placed in a second gut segment. Superior mesenteric artery $\left(Q_{S M A}\right)$ and aortic $\left(Q_{\text {aorta }}\right)$ flows were measured using ultrasonic flow probes. After $4 \mathrm{~h}$ of fluid resuscitation, tissue specimens were immediately removed for estimations of gut and lung edema. There were no differences in global and regional perfusion variables, lung wet-to-dry weight ratios and oxygenation indices between groups. Gut wet-to-dry weight ratio was significantly lower in the crystalloid/colloidtreated group $(4.9 \pm 1.5)$ than in the crystalloid-treated group $(7.3 \pm 2.4)(P<0.05)$. In this model of intestinal ischemia, fluid resuscitation with crystalloids caused more gut edema than a combination of crystalloids and colloids.
\end{abstract}

Key words: Fluid resuscitation; Colloids; Crystalloids; Splanchnic ischemia; Intestinal edema

Publication supported by FAPESP.

Received December 6, 2007. Accepted June 24, 2008

\section{Introduction}

The splanchnic region may play an important role in the development of multiple organ failure (1). During gut ischemia, neutrophils become inappropriately activated, degranulating prematurely and releasing toxic elastases and reactive oxygen species inside or immediately outside the vasculature. These substances can injure the microcirculatory endothelium, increasing vascular permeability and allowing fluids, cells, and macromolecules to leak out and cause tissue edema (2). Inadequate gastrointestinal perfusion and oxygenation may result in the passage of trans- location of bacteria, endotoxins, and vasoactive substances into the systemic circulation (3). Even in the absence of bowel necrosis, fluid shifts may result in hidden fluid loss with large quantities of fluids released into the peritoneal cavity.

Early circulatory changes in massive intestinal ischemia are mainly due to hypovolemia (3). Fluid resuscitation may consist of natural or artificial colloids or crystalloids. Although there is no clear evidence-based support for one type of fluid over another in regard to restoration of central hemodynamics (4), the type of fluid used during resuscitation may have a potentially important impact on fluid over- 
load of the lung and gut. The infusion of large amounts of crystalloids may result in gut edema and increase the risk of intra-abdominal hypertension resulting in abdominal compartment syndrome (5).

Crystalloids are water-based solutions containing lowmolecular weight molecules freely permeable to the vascular membrane and are therefore distributed mainly in the interstitial and/or intercellular compartments $(6,7)$. Colloids are high-molecular weight polymers that are retained longer in the intravascular space thus requiring less total volume than crystalloid solutions to achieve the same resuscitation end-points. There is the possibility that with increased microvascular permeability, colloids could migrate into the interstitium where they would favor fluid retention and worsen interstitial edema (8). Therefore, we evaluated the impact of two different regimens of fluid administration on global and regional hemodynamics as well as on intestinal and pulmonary edema in a splanchnic hypoperfusion model induced by the ligation of the superior mesenteric artery in rabbits. We used a hydroxyethyl starch (HES) solution, a synthetic colloid formed from substituted branched-chain amylopectin with as much as $40 \%$ of maximum volume expansion persisting for $24 \mathrm{~h} \mathrm{(9)}$ and lactated Ringer solution as the crystalloid fluid.

\section{Material and Methods}

\section{Instrumentation}

Sixteen New Zealand rabbits (2.9-3.3 kg body weight) were handled according to the regulations of the local Animal Care Committee after institutional approval for animal investigations was obtained. Induction doses of ketamine $(20 \mathrm{mg} / \mathrm{kg}$ ) and xylazine $(4 \mathrm{mg} / \mathrm{kg}$ ) were given intramuscularly for sedation and anesthesia, followed by a continuous infusion of ketamine $\left(15-35 \mathrm{mg} \cdot \mathrm{kg}^{-1} \cdot \mathrm{h}^{-1}\right)$ started $3 \mathrm{~h}$ after induction. An intravenous catheter was inserted into an ear vein for venous access (18 G x 2" Surflo iv catheter; USA) and $20 \mathrm{~mL} 0.9 \%$ saline was given as a bolus. A tracheotomy was performed and the animals were ventilated (Inter 5, Intermed, Brazil) with $40-60 \% \mathrm{FiO}_{2}$, tidal volume of 7 to 10 $\mathrm{mL} / \mathrm{kg}$ and respiratory rate of 40 breaths/min further adjusted to maintain a $\mathrm{PaO}_{2}>80 \mathrm{mmHg}$ and $\mathrm{aaCO}$ between 35 and $45 \mathrm{mmHg}$. A 16-G polyethylene catheter was inserted into the right carotid artery and connected to a pressure transducer to obtain continuous recording of arterial pressure. Another catheter (Surflo iv catheter, $22 \mathrm{G} \times 2$ ") was placed in the jugular vein for venous access and central venous pressure (CVP) measurements.

\section{Surgical preparation}

A midline laparotomy was performed and ultrasonic flow probes (Transonic System Inc., USA) were placed around the superior mesenteric artery $\left(Q_{S M A}\right)$ and the abdominal aorta $\left(Q_{a o r t a}\right)$ just above the origin of the celiac trunk to measure flow continuously. A bowel segment was delineated in the mid ileum to allow measurement of the lactate released from the gut mucosa. An antimesenteric enterotomy was performed and inflow and outflow catheters were placed to delimit a closed 5-cm segment of the ileum. The bowel segment was carefully rinsed with heated $\left(37^{\circ} \mathrm{C}\right)$ saline, before a sodium phosphate buffer, $\mathrm{pH} 7.2$, was infused at a rate of $8 \mathrm{~mL} / \mathrm{h}$. The lumen of the proximal catheter was used for continuous infusion and the lumen of the distal catheter was used to recover the gut luminal perfusate every hour. The details of this technique were described elsewhere $(10,11)$. In a second gut segment, a tonometric catheter (TRIP ${ }^{\circledR}$ Tonometry Catheter, Datex, Finland) was placed through a minimal antimesenteric wall incision and secured with a purse-string suture. A small drain was placed in the peritoneum to withdraw peritoneal fluid. Body temperature was maintained between $36-38^{\circ} \mathrm{C}$ with a heat lamp. The animals were allowed to recover for 60 min before starting the experimental protocol.

\section{Experimental protocol}

Fluid resuscitation was started immediately after a bolus of $20 \mathrm{~mL} 0.9 \%$ saline into the ear vein and was maintained until the end of the experiment as follows: group I (crystalloid plus colloid; $\mathrm{N}=9$ ) received $12 \mathrm{~mL} \cdot \mathrm{kg}^{-1} \cdot \mathrm{h}^{-1}$ lactated Ringer solution and a bolus of $20 \mathrm{~mL} / \mathrm{kg} \mathrm{6 \%} \mathrm{HES} \mathrm{(MW} \mathrm{200,000} \mathrm{D/}$ 0.5 , Haes-Steril, Fresenius, Germany); group II (crystalloid, $\mathrm{N}=7$ ) received $36 \mathrm{~mL} \cdot \mathrm{kg}^{-1} \cdot \mathrm{h}^{-1}$ lactated Ringer solution and a bolus of $20 \mathrm{~mL} / \mathrm{kg} 0.9 \%$ saline. After baseline measurements, ligation of superior mesenteric artery was performed. Mean arterial pressure, CVP, $Q_{\text {aorta, }} Q_{S M A}$, ileal mucosal $\mathrm{PCO}_{2}$, peritoneal, serum and luminal gut lactate perfusate were measured every hour for $4 \mathrm{~h}$.

\section{Analytical methods}

Arterial samples were obtained for blood gas analysis (ABL-30, Radiometer, Denmark). Blood (700 $\mu \mathrm{L})$, peritoneal fluid and gut luminal perfusate samples for lactate analysis were collected in fluoride-sodium heparin coated tubes, stored on ice and measurements were carried out within $5 \mathrm{~min}$. Serum osmolality was determined by freezing point measurement (Osmette A, Precision Systems, USA).

\section{Tonometry}

For tonometry measurements, $1 \mathrm{~mL}$ saline was placed in the silicone balloon of the tonometer and allowed to equilibrate for $30 \mathrm{~min}$. The first $0.7 \mathrm{~mL}$ removed was discarded and analysis was performed immediately on the remaining 
$0.3 \mathrm{~mL}$ in a blood gas analyzer (ABL-30). lleum $\mathrm{PCO}_{2}$ was corrected for incomplete equilibration time during the 30-min sampling periods multiplying $\mathrm{PCO}_{2}$ by 1.24 . The ileal mucosal-arterial $\mathrm{PCO}_{2}$ gradient $\left(\mathrm{PCO}_{2}\right.$-gap) was calculated.

\section{Grading of organ damage}

Each animal received a lethal injection of sodium pentobarbital at the end of the experiment $(4 \mathrm{~h}$ after the beginning of the experiment). Segments of the distal ileum and left lung were harvested and immediately fixed in $10 \%$ formaldehyde-saline. The tissue was embedded in paraffin wax, sectioned serially, and stained with hematoxylin-eosin. Intestinal morphological characteristics were evaluated under light microscopy. Mucosal histology was graded as previously described (12) using the following scale: grade $0=$ normal mucosa; grade 1 = sub-epithelial space formation; grade 2 = extension of the sub-epithelial space with moderate lifting of the epithelial layer from the lamina propria; grade $3=$ massive epithelial lifting down the sides of the villi; grade 4 = denuded villi with lamina propria and exposed dilated capillaries; grade $5=$ digestion and disintegration of the lamina propria, hemorrhage and ulceration. In lung biopsies, organ injury was determined according to the degree of edema and was classified semi-quantitatively as follows: grade $0=$ none (normal); grade 1 = slight edema of the alveolar walls; grade 2 = moderate edematous thickening of alveolar walls with occasional alveoli containing coagulated edema fluid; grade 3 = extensive occurrence of alveolar and interstitial edema (13). The pathologist who evaluated intestinal mucosal damage was blind to the treatment.

\section{Wet-to-dry weight ratio}

At the end of the experiment, the distal $10 \mathrm{~cm}$ of the ileum and left lung were harvested immediately, weighed and heated at $100^{\circ} \mathrm{C}$ in a gravity convection oven for $24 \mathrm{~h}$ and reweighed. Wet-to-dry weight ratios were calculated.

\section{Data analysis}

Data are reported as mean $\pm \mathrm{SD}$. Statistical significance was tested by analysis of variance for repeated measurements (ANOVA). The Student $t$-test with Bonferroni adjustment was used for multiple comparisons. The extent of histological damage between groups was evaluated using the Mann-Whitney rank sum test. $P<0.05$ was considered to be statistically significant.

\section{Results}

After occlusion of the superior mesenteric artery, the $\mathrm{PCO}_{2}$-gap (Table 1) increased for both groups (group I:

Table 1. Global and regional perfusion measurements and hemodynamic variables.

\begin{tabular}{|c|c|c|c|c|c|}
\hline & \multicolumn{5}{|c|}{ Time after superior mesenteric artery occlusion } \\
\hline & $\mathrm{Oh}$ & $1 \mathrm{~h}$ & $2 \mathrm{~h}$ & $3 \mathrm{~h}$ & $4 \mathrm{~h}$ \\
\hline \multicolumn{6}{|c|}{$\mathrm{PCO}_{2}$-gap (Torr) } \\
\hline Group I & $0.25 \pm 8.1$ & $36 \pm 28^{*}$ & $63 \pm 43^{*}$ & $57 \pm 37^{\star}$ & $58 \pm 46^{*}$ \\
\hline Group II & $1.20 \pm 8.1$ & $27 \pm 13^{*}$ & $48 \pm 23^{*}$ & $56 \pm 13^{*}$ & $49 \pm 25^{*}$ \\
\hline \multicolumn{6}{|c|}{ Gut lactate (mEq/L) } \\
\hline Group I & $0.68 \pm 0.59$ & $1.82 \pm 0.88$ & $2.94 \pm 0.38^{*}$ & $3.51 \pm 1.49^{*}$ & $3.26 \pm 1.57^{*}$ \\
\hline Group II & $0.77 \pm 0.74$ & $1.88 \pm 1.02$ & $2.50 \pm 0.70^{*}$ & $2.82 \pm 0.64^{*}$ & $3.20 \pm 0.77^{*}$ \\
\hline \multicolumn{6}{|c|}{ CVP $\left(\mathrm{cmH}_{2} \mathrm{O}\right)$} \\
\hline Group I & $11 \pm 2.3$ & $11 \pm 2.0$ & $12 \pm 2.5$ & $11 \pm 0.5$ & $11 \pm 1.2$ \\
\hline Group II & $12 \pm 4.0$ & $13 \pm 4.5$ & $14 \pm 3.1$ & $14 \pm 2.5^{+}$ & $14 \pm 5.0^{+}$ \\
\hline \multicolumn{6}{|c|}{ MAP (mm Hg) } \\
\hline Group I & $69 \pm 8$ & $77 \pm 14$ & $77 \pm 7$ & $85 \pm 10^{*}$ & $86 \pm 10^{*}$ \\
\hline Group II & $68 \pm 12$ & $78 \pm 15$ & $82 \pm 11$ & $85 \pm 9^{*}$ & $91 \pm 12^{*}$ \\
\hline \multicolumn{6}{|c|}{ Peritonial lactate (mEq/L) } \\
\hline Group I & $3.4 \pm 0.8$ & $4.6 \pm 0.7$ & $5.3 \pm 1.0^{*}$ & $5.9 \pm 1.4^{*}$ & $6.1 \pm 1.6^{*}$ \\
\hline Group II & $4.1 \pm 0.9$ & $5.4 \pm 0.9$ & $5.0 \pm 1.7$ & $5.9 \pm 1.7$ & $6.5 \pm 1.6^{*}$ \\
\hline \multicolumn{6}{|c|}{ Serum lactate (mEq/L) } \\
\hline Group I & $3.2 \pm 1.1$ & $3.8 \pm 1.3$ & $4.2 \pm 1.5$ & $4.8 \pm 1.4$ & $5.0 \pm 1.8$ \\
\hline Group II & $4.0 \pm 0.9$ & $4.0 \pm 0.7$ & $3.7 \pm 0.7$ & $4.2 \pm 1.0$ & $5.1 \pm 1.3$ \\
\hline
\end{tabular}

Data are reported as means $\pm \mathrm{SD}$. Group I $(\mathrm{N}=9)$ received $12 \mathrm{~mL} \cdot \mathrm{kg}^{-1} \cdot \mathrm{h}^{-1}$ lactated Ringer solution and $20 \mathrm{~mL} / \mathrm{kg}$ hydroxyethyl starch solution. Group II (N = 7) received $36 \mathrm{~mL} \cdot \mathrm{kg}^{-1} \cdot \mathrm{h}^{-1}$ lactated Ringer solution and $20 \mathrm{~mL} / \mathrm{kg} 0.9 \%$ saline. $\mathrm{PCO}_{2}-$ gap $=$ ileal mucosalarterial $\mathrm{PCO}_{2}$ gradient; $\mathrm{CVP}=$ central venous pressure; $\mathrm{MAP}=$ mean arterial pressure.

${ }^{+} \mathrm{P}<0.05$ vs group I ( $t$-test). ${ }^{*} \mathrm{P}<0.05$ vs baseline (ANOVA). 
from $0.25 \pm 8.1$ at $0 \mathrm{~h}$ to $58 \pm 46$ torr at $4 \mathrm{~h}$; group II: from 1.2 \pm 8.1 at $0 \mathrm{~h}$ to $49 \pm 25$ torr at $4 \mathrm{~h} ; \mathrm{P}<0.05$ for $4 \mathrm{~h}$ compared to $0 \mathrm{~h}$ ). However, there were no statistical differences between the two groups. Likewise, the luminal gut lactate concentrations increased similarly for both groups (group I: from $0.68 \pm 0.59$ at $0 \mathrm{~h}$ to $3.26 \pm 1.57 \mathrm{mEq} / \mathrm{L}$ at $4 \mathrm{~h}$; group II: from $0.77 \pm 0.74$ to $3.20 \pm 0.77 \mathrm{mEq} / \mathrm{L}$ at $4 \mathrm{~h}, \mathrm{P}<0.05$ for $4 \mathrm{~h}$ compared to $0 \mathrm{~h}$ ). The data indicate severe alterations of gut perfusion. Similarly, no significant differences were detected between the two groups in $Q_{\text {aorta }}$, and $Q_{S M A}$ (data not shown). CVP, mean arterial pressure, peritoneal and arterial blood lactate concentrations are also reported in Table 1. CVP was significantly higher in group II at 3 and 4 $h$ than in group I $(P<0.05)$. Osmolality was significantly higher in group I $(299 \pm 74 \mathrm{mOsm} / \mathrm{L})$ than in group II $(264$ $\pm 10 \mathrm{mOsm} / \mathrm{L})$ at $4 \mathrm{~h}(\mathrm{P}<0.05)$.

Gut wet-to-dry weight ratio was significantly lower in group I than in group II $(4.9 \pm 1.5$ vs $7.3 \pm 2.4, \mathrm{P}<0.05)$. There were no significant differences in lung wet-to-dry weight ratios $(4.5 \pm 1.1$ vs $4.9 \pm 1.3)$ and oxygenation indices $\left(\mathrm{PO}_{2} / \mathrm{FiO}_{2}\right.$ ratio) between the two groups (baseline: $421 \pm 141$ vs $458 \pm 162 ; 2$ h: $448 \pm 143$ vs $438 \pm 78 ; 4$ h: 425 \pm 434 vs $479 \pm 22$, for group I and group II, respectively).

Histological specimens from the gut showed a similar degree of injury in both groups (group I: 2 specimens were grade $0 ; 5$ specimens were grade 4 ; group II: 1 specimen was grade $1 ; 5$ specimens were grade $4 ; 1$ specimen was grade 5). Histological specimens from lungs were graded as 0 for all samples in both groups.

\section{Discussion}

Mesenteric ischemia can occur as a consequence of either vascular disease or generalized shock. (1). If the ischemia is extensive, the injury to the gut mucosa might lead to the loss of large amounts of water and proteins through the injured mucosa. In the present study, the 4-h occlusion of the superior mesenteric artery without reperfusion caused severe histological alterations in the gut, particularly denuded villi. The crystalloid-treated group showed significantly larger amounts of intestinal tissue hydration than the crystalloid/colloid-treated group, as reflected by an increased wet-to-dry tissue weight ratio.

Edema of the intestine may have serious consequences (14). Gut edema may be associated with postoperative gastrointestinal dysfunction, impairment of tissue oxygenation, and even more importantly, increased intra-abdominal pressure that may result in abdominal compartment syndrome $(5,15-17)$. No physiologic or histologic evidence of lung injury was demonstrable, probably due to the short 4-h occlusion and observation period.
In anesthetized dogs undergoing extracorporeal life support, an HES priming solution decreases intestinal edema by the maintenance of the plasma-to-interstitial colloid osmotic pressure (COP) gradient and the ability of the membrane to selectively limit the passage of macromolecules (18). Resuscitation fluids can also influence inflammatory and immune responses. It has been shown that HES effectively decreases leukocyte adherence, improves endothelial integrity, decreases apoptosis and attenuates tissue edema and injury in different animal and human models of fluid resuscitation (19-23).

If we were to extrapolate our results with rabbits to patients, we might conclude that the use of colloids could be better than crystalloids in patients of high risk of developing gastrointestinal dysfunction because they may cause less intestinal edema, but this has not been demonstrated unambiguously. In major trauma patients, supranormal resuscitation was associated with more lactated Ringer solution infusion, decreased intestinal perfusion and an increased incidence of abdominal compartment syndrome, multiple organ failure, and death but a direct comparison with colloid solution was not made (5). Restrictive strategies for crystalloid administration during gastrointestinal surgeries have been shown to improve some outcomes (24-26). Hemodynamic care incorporating HES after cardiac surgery has been shown to significantly reduce the incidence of gut hypoperfusion, decrease postoperative complications and the length of hospitalization (27). Nevertheless, several studies were unable to demonstrate a survival benefit favoring the use of colloids in various clinical settings (28-30). Fluid resuscitation with $10 \%$ HES $200 / 0.5$ is harmful in patients with severe sepsis. At recommended doses, it causes renal impairment, and at high doses, it impairs long-term survival (31). It is possible that the more recent third-generation HES preparation with a low degree of substitution may overcome the adverse effects of the older colloid solutions (32).

An ischemic insult to an organ causes cell damage that may progress to cell death. In the present study, an experimental ischemic infarction model instead of the more commonly used ischemia and reperfusion model was used to evaluate the effects of early fluid resuscitation before blood flow is restored. It is possible that an even greater edema effect would have been seen if an ischemia-reperfusion model was used because even greater edema formation is expected to occur after reperfusion.

One important limitation of our study is the difficulty in chosing the adequate amount of fluids to be used in the control group. The volume used, $36 \mathrm{~mL} \cdot \mathrm{kg}^{-1} \cdot \mathrm{h}^{-1}$, is open to question. Nevertheless, larger volumes of isotonic crystalloids than colloid solutions are required to replete the 
intravascular volume. Thus, we used three times more crystalloids in group II in order to achieve similar plasma volume expansion (33). Importantly, hemodynamic and perfusion parameters were restored similarly with colloids plus crystalloids or crystalloids alone during severe gut ischemia but with a significantly higher CVP with the use of a higher volume of crystalloids, which could have caused mesenteric venous hypertension and influenced edema formation (14).

Our results suggest that the use of a colloid solution in addition to a lower volume of crystalloid solution causes less intestinal edema during gut ischemia in rabbits.

\section{References}

1. Brinkmann A, Calzia E, Trager K, Radermacher P. Monitoring the hepato-splanchnic region in the critically ill patient. Measurement techniques and clinical relevance. Intensive Care Med 1998; 24: 542-556.

2. Faust-Chan R, Hybertson B, Flores SC, Wright RM, Repine JE. Initiation and tolerance to acute lung injury: yin-yang mechanisms involving interleukin-1. Chest 1999; 116: 102S103 S.

3. Ljungdahl M, Rasmussen I, Raab Y, Hillered L, Haglund U. Small intestinal mucosal $\mathrm{pH}$ and lactate production during experimental ischemia-reperfusion and fecal peritonitis in pigs. Shock 1997; 7: 131-138.

4. Dellinger RP, Carlet JM, Masur H, Gerlach H, Calandra T, Cohen J, et al. Surviving Sepsis Campaign guidelines for management of severe sepsis and septic shock. Intensive Care Med 2004; 30: 536-555.

5. Balogh Z, McKinley BA, Cocanour CS, Kozar RA, Valdivia $A$, Sailors RM, et al. Supranormal trauma resuscitation causes more cases of abdominal compartment syndrome. Arch Surg 2003; 138: 637-642.

6. Boldt J. Fluid choice for resuscitation of the trauma patient: a review of the physiological, pharmacological, and clinical evidence. Can J Anaesth 2004; 51: 500-513.

7. Choi PT, Yip G, Quinonez LG, Cook DJ. Crystalloids vs colloids in fluid resuscitation: a systematic review. Crit Care Med 1999; 27: 200-210.

8. Marx G. Fluid therapy in sepsis with capillary leakage. Eur J Anaesthesiol 2003; 20: 429-442.

9. Treib J, Baron JF, Grauer MT, Strauss RG. An international view of hydroxyethyl starches. Intensive Care Med 1999; 25: 258-268.

10. Lobo SM, De Backer D, Sun Q, Tu Z, Dimopoulos G, Preiser $\mathrm{JC}$, et al. Gut mucosal damage during endotoxic shock is due to mechanisms other than gut ischemia. J Appl Physiol 2003; 95: 2047-2054.

11. Lobo SM, Orrico SR, Queiroz MM, Cunrath GS, Chibeni GS, Contrin LM, et al. Pneumonia-induced sepsis and gut injury: effects of a poly-(ADP-ribose) polymerase inhibitor. $J$ Surg Res 2005; 129: 292-297.

12. Chiu CJ, McArdle AH, Brown R, Scott HJ, Gurd FN. Intestinal mucosal lesion in low-flow states. I. A morphological, hemodynamic, and metabolic reappraisal. Arch Surg 1970; 101: 478-483.

13. Nahum A, Hoyt J, Schmitz L, Moody J, Shapiro R, Marini JJ. Effect of mechanical ventilation strategy on dissemination of intratracheally instilled Escherichia coli in dogs. Crit Care Med 1997; 25: 1733-1743.
14. Moore-Olufemi SD, Xue $\mathrm{H}$, Attuwaybi BO, Fischer U, Harari $\mathrm{Y}$, Oliver $\mathrm{DH}$, et al. Resuscitation-induced gut edema and intestinal dysfunction. J Trauma 2005; 58: 264-270.

15. Bennett-Guerrero E, Welsby I, Dunn TJ, Young LR, Wahl TA, Diers TL, et al. The use of a postoperative morbidity survey to evaluate patients with prolonged hospitalization after routine, moderate-risk, elective surgery. Anesth Analg 1999; 89: 514-519.

16. Mythen MG. Postoperative gastrointestinal tract dysfunction. Anesth Analg 2005; 100: 196-204.

17. Baum TD, Wang H, Rothschild HR, Gang DL, Fink MP. Mesenteric oxygen metabolism, ileal mucosal hydrogen ion concentration, and tissue edema after crystalloid or colloid resuscitation in porcine endotoxic shock: comparison of Ringer's lactate and 6\% hetastarch. Circ Shock 1990; 30: 385-397.

18. Cox CS Jr, Brennan M, Allen SJ. Impact of hetastarch on the intestinal microvascular barrier during ECLS. J Appl Physiol 2000; 88: 1374-1380.

19. Rocha-e-Silva M, Poli de Figueiredo LF. Small volume hypertonic resuscitation of circulatory shock. Clinics 2005; 60: 159-172.

20. Mittlmeier T, Vollmar B, Menger MD, Schewior L, Raschke $M$, Schaser KD. Small volume hypertonic hydroxyethyl starch reduces acute microvascular dysfunction after closed soft-tissue trauma. J Bone Joint Surg Br 2003; 85: 126-132.

21. Nielsen VG, Tan S, Brix AE, Baird MS, Parks DA. Hextend (hetastarch solution) decreases multiple organ injury and xanthine oxidase release after hepatoenteric ischemia-reperfusion in rabbits. Crit Care Med 1997; 25: 1565-1574.

22. Murao $Y$, Hata M, Ohnishi K, Okuchi K, Nakajima Y, Hiasa $Y$, et al. Hypertonic saline resuscitation reduces apoptosis and tissue damage of the small intestine in a mouse model of hemorrhagic shock. Shock 2003; 20: 23-28.

23. Boldt J, Ducke M, Kumle B, Papsdorf M, Zurmeyer EL. Influence of different volume replacement strategies on inflammation and endothelial activation in the elderly undergoing major abdominal surgery. Intensive Care Med 2004; 30: 416-422.

24. Lobo DN, Bostock KA, Neal KR, Perkins AC, Rowlands BJ, Allison SP. Effect of salt and water balance on recovery of gastrointestinal function after elective colonic resection: a randomised controlled trial. Lancet 2002; 359: 1812-1818.

25. Brandstrup B, Tonnesen H, Beier-Holgersen R, Hjortso E, Ording $\mathrm{H}$, Lindorff-Larsen $\mathrm{K}$, et al. Effects of intravenous fluid restriction on postoperative complications: comparison of two perioperative fluid regimens: a randomized assessor- 
blinded multicenter trial. Ann Surg 2003; 238: 641-648.

26. Nisanevich V, Felsenstein I, Almogy G, Weissman C, Einav $\mathrm{S}$, Matot I. Effect of intraoperative fluid management on outcome after intraabdominal surgery. Anesthesiology 2005; 103: 25-32.

27. Mythen MG, Webb AR. Perioperative plasma volume expansion reduces the incidence of gut mucosal hypoperfusion during cardiac surgery. Arch Surg 1995; 130: 423-429.

28. Schierhout G, Roberts I. Fluid resuscitation with colloid or crystalloid solutions in critically ill patients: a systematic review of randomised trials. BMJ 1998; 316: 961-964.

29. Cochrane Injuries Group Albumin Reviewers. Human albumin administration in critically ill patients: systematic review of randomised controlled trials. BMJ 1998; 317: 235-240.

30. Finfer S, Bellomo R, Boyce N, French J, Myburgh J, Norton
R. A comparison of albumin and saline for fluid resuscitation in the intensive care unit. N Engl J Med 2004; 350: 22472256.

31. Brunkhorst FM, Engel C, Bloos F, Meier-Hellmann A, Ragaller $\mathrm{M}$, Weiler $\mathrm{N}$, et al. Intensive insulin therapy and pentastarch resuscitation in severe sepsis. $N$ Engl $J$ Med 2008; 358: 125-139.

32. Blasco V, Leone M, Antonini F, Geissler A, Albanese J, Martin C. Comparison of the novel hydroxyethylstarch 130/ 0.4 and hydroxyethylstarch 200/0.6 in brain-dead donor resuscitation on renal function after transplantation. $\mathrm{Br} J$ Anaesth 2008; 100: 504-508.

33. Grocott MP, Mythen MG, Gan TJ. Perioperative fluid management and clinical outcomes in adults. Anesth Analg 2005; 100: 1093-1106. 